Volume 9, No.5, September - October 2020

International Journal of Advanced Trends in Computer Science and Engineering

Available Online at http://www.warse.org/IJATCSE/static/pdf/file/ijatcse262952020.pdf

https://doi.org/10.30534/ijatcse/2020/262952020

\title{
Enhancement of Peer to Peer Smart Tracking System (P2P-STS)
}

\author{
Dr. Omar Khattab ${ }^{1}$, Hessah Matbaqi ${ }^{2}$, Hussain Dashti ${ }^{3}$, Rajaa Abdullah ${ }^{4}$ \\ ${ }^{1}$ Assistant Professor, Dept.of Computer Science \& Engineering \\ ${ }^{2}$ BEng Student, Computer Engineering Program \\ ${ }^{3}$ BEng Student, Computer Engineering Program \\ ${ }^{4}$ BEng Student, Computer Engineering Program \\ Kuwait College of Science and Technology (KCST), Kuwait
}

\begin{abstract}
A Peer-to-Peer (P2P) network is a group of computers which are directly connected to each other to share resources without needing to an intermediate node, where each computer on a P2P network can play the role of a server and a client simultaneously. In this paper, a research work about a P2P network has been considered, which theoretically confined in surveying and discussing many P2P methods, whereas no empirical work was provided. Therefore, this paper has thoroughly analyzed several real small businesses whether they use a P2P network or not (P2P vs. non-P2P), and come up with an optimized practice solution in using and utilizing the vital main features of P2P network: Peep to Peer Smart Tracking System (P2P-STS).
\end{abstract}

Key words: Peer-to-Peer (P2P), Radio Frequency Identification (RFID), Tracking Systems

\section{INTRODUCTION}

Unlike the active directory network server [1], a Peer-to-Peer (P2P) network is more prevalent in the different applications, where it is a distributed system without a central node. [2].

Some of its main features are mentioned below [3]:

- It is a reliable network, where a failure of any computer doesn't disrupt the functioning of other computer.

- A dedicated server is not required, where the available resources are shared by all peers.

- A specialized IT staff is not required, as each user account is an administrator on his/her computer.

- Installation and configuration are simple.

- Lower cost compared with the server network.

This paper has thoroughly analyzed several real small businesses in Kuwait whether they use a P2P network or not (P2P vs. non-P2P), and come up with an optimized practice solution in using and utilizing the vital main features of P2Pnetwork: Peep to Peer Smart Tracking System (P2P-STS).
The rest of the paper is organized as follows: Section 2 presents related works of P2P network. Section 3 presents a comprehensive analysis of $\mathrm{P} 2 \mathrm{P}$ vs. non-P2P. A fair discussion of $\mathrm{P} 2 \mathrm{P}$ is presented in section 4.The proposed $\mathrm{P} 2 \mathrm{P}-\mathrm{TS}$ design and implementation is presented in section 5. Finally, a conclusion work is given in section 6 .

\section{RELATED WORKS OF P2P}

This paper considers a research work [2] about a P2P network, which surveyed fifteen methods. It has been noticed in [2] that it theoretically confined in surveying and discussing many $\mathrm{P} 2 \mathrm{P}$ methods in terms of future scope, advantages and disadvantages, whereas no empirical work was provided.

\section{A COMPREHENSIVE ANALYSIS OF THE P2P VS. NON-P2P}

We have thoroughly analyzed several real small businesses in Kuwait in order to recognize the nature of their business and to get a better understanding about their system. We have divided our survey into two main parts: the first, for the businesses which already use P2P, while the second, for the businesses which don't use it (non-P2P). In our survey, we have concentrated on the following main features: Windows version, file sharing, map drive, file permissions, NTFS permissions, sharing printer, remote desktop and tracking system, as depicted in Figure 1. Table 1 and Figure 2-Figure 12 show a productive outcome of the comprehensive analysis of P2P vs. non-P2P.

\section{A FAIR DISCUSSION OF P2P}

It has been noticed from the section 3 that the most of P2P businesses have not effectively use the main features of P2P, especially the "remote desktop" and the "tracking system", which have scored a minimum number of use (5\%, Figure 8$)$, (25\%, Figure 9); respectively. Where, the feature of remote desktop allows users to run a desktop of another computer remotely [4].

Radio Frequency Identification (RFID) is a tracking system which can be effectively integrated with a P2P network [5]. It is used in various applications such as aviation, construction and facility management, health, retailing, logistics and security [6]. 


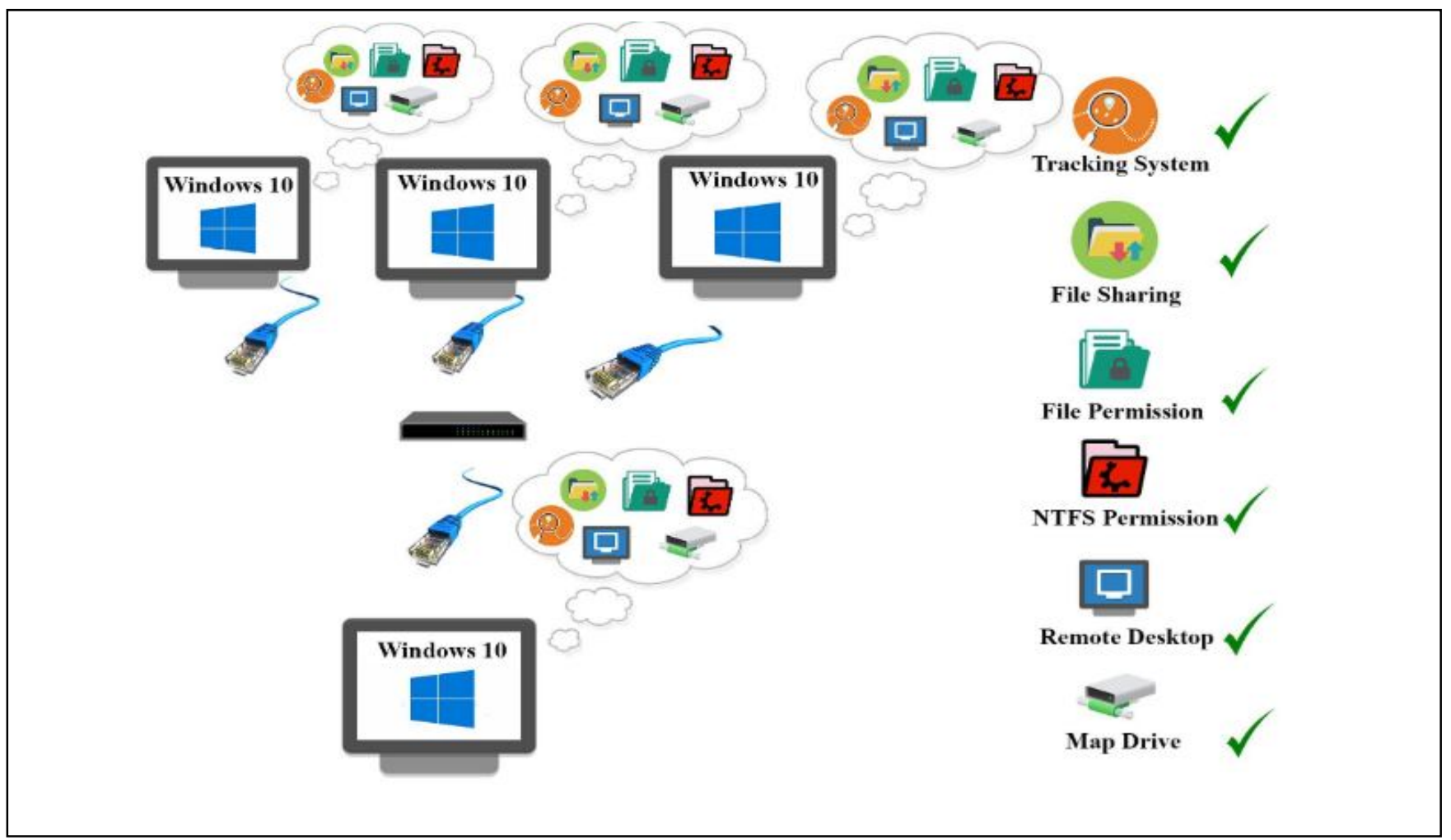

Figure 1: The Features of P2P Network

Therefore, it would be necessary to come up with an optimized practice solution in using and utilizing the vital main features of P2P network, especially the "tracking system" as $80 \%$ of $\mathrm{P} 2 \mathrm{P}$ businesses is keen to improve their system. This is depicted in Figure 11.

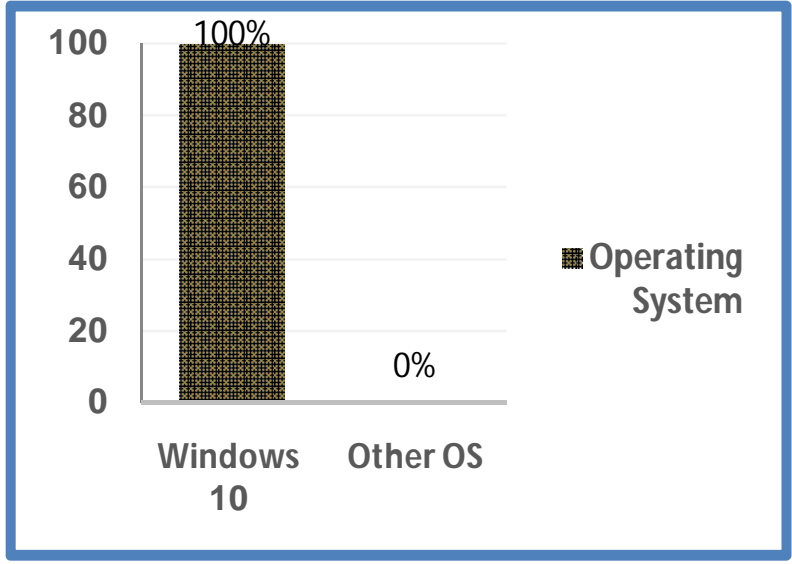

Figure 2: Windows 10 vs. Other Operating Systems

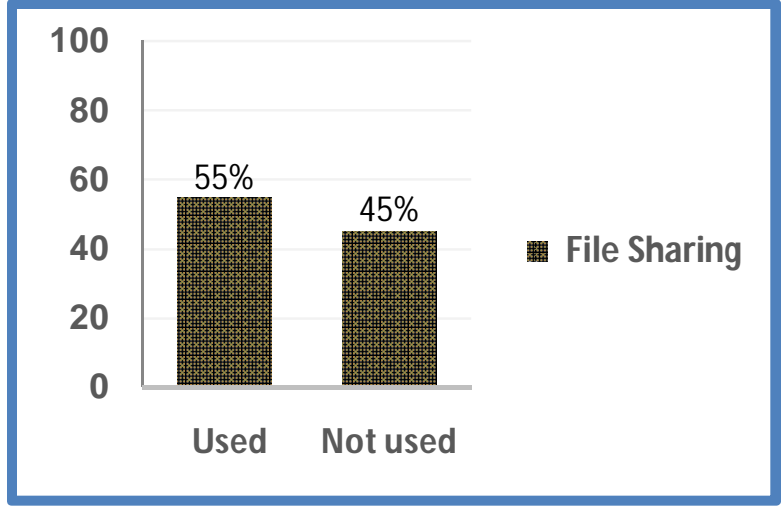

Figure 3: File Sharing vs. non-File Sharing

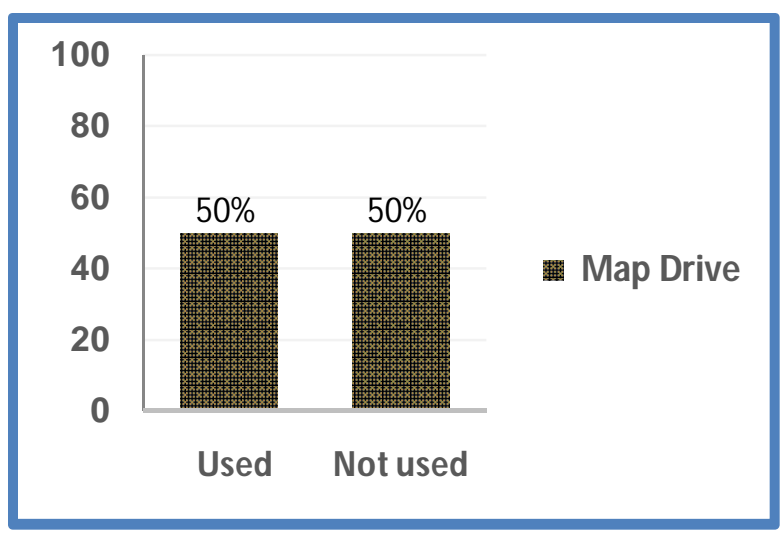

Figure 4: Map Drive vs. non-Map Drive 


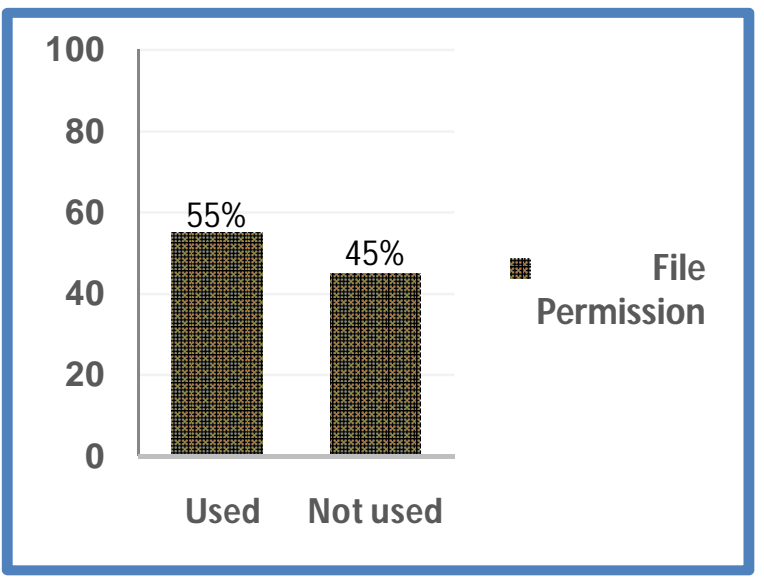

Figure 5:File Permission vs. non-File Permission

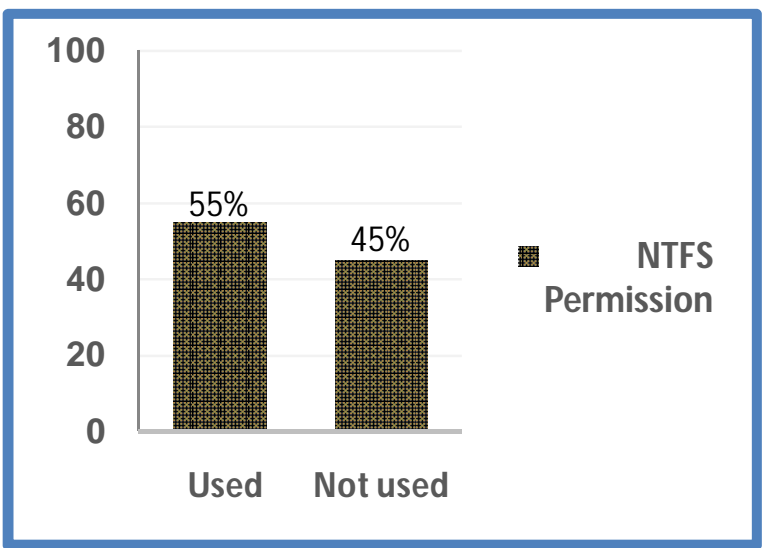

Figure 6:NTFS Permission vs. non-NTFS Permission

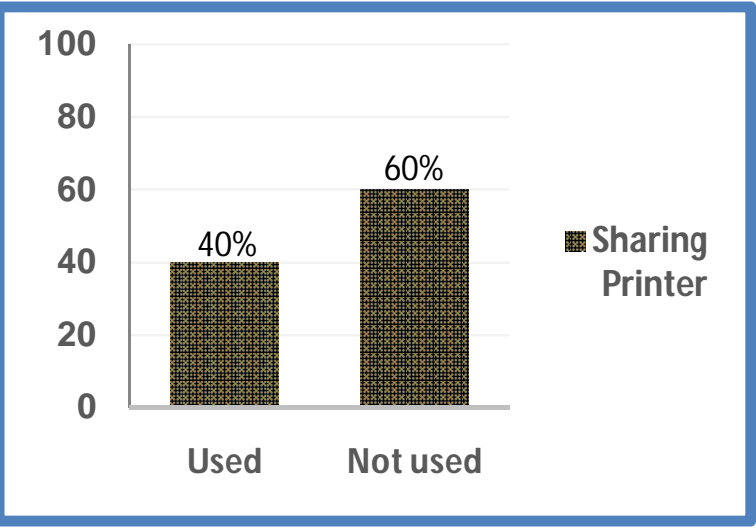

Figure 7: Sharing Printer vs. non-Sharing Printer

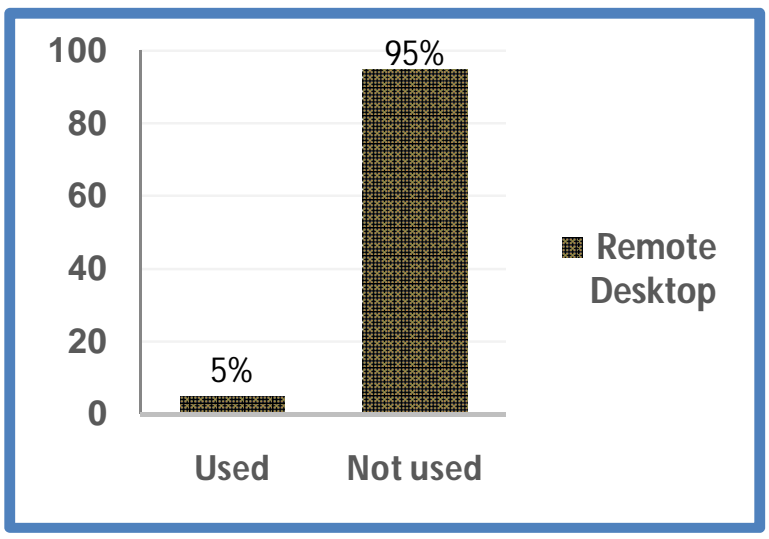

Figure 8:Remote Desktop vs. non-Remote Desktop

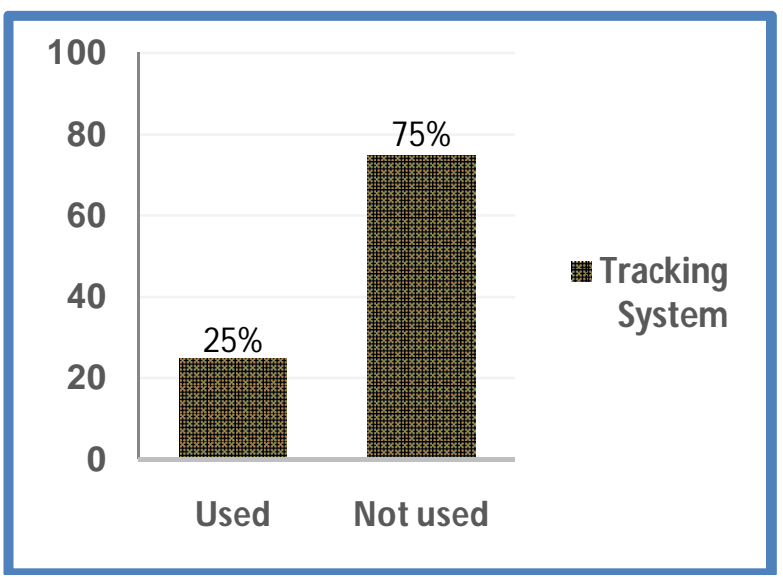

Figure 9: Tracking System vs. non-Tracking System

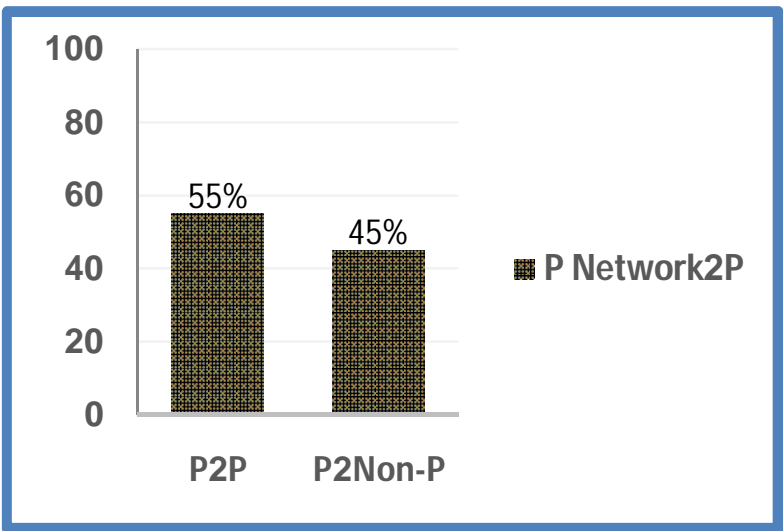

Figure 10:P2P vs. non-P2P

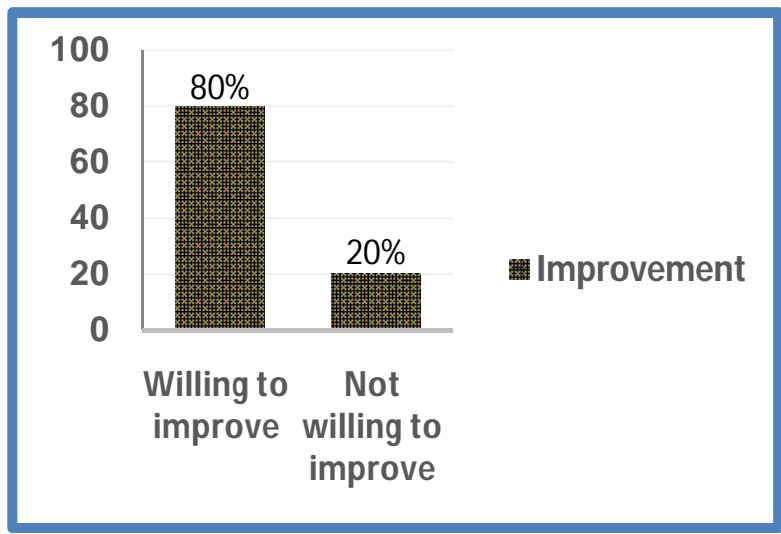

Figure 11: Willing to Improve vs. not Willing to Improve

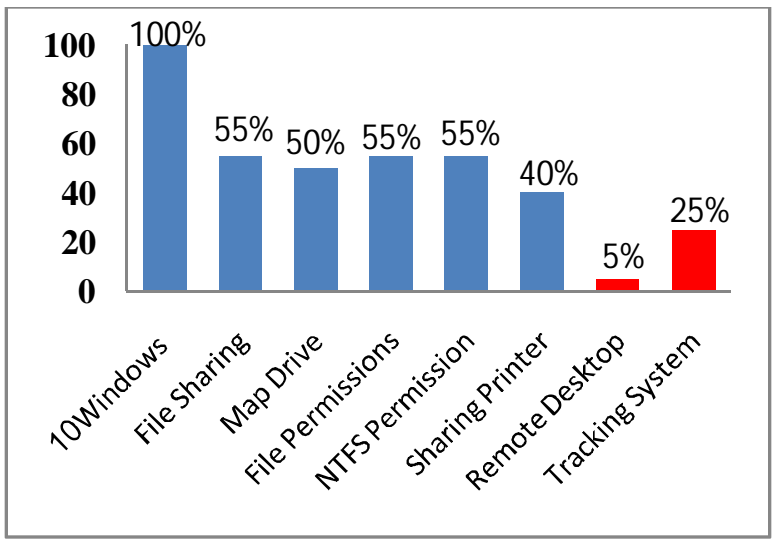

Figure 12: Comparison of Features of P2P Network 
Table 1: The Comprehensive Comparison of Features of P2P Network

\begin{tabular}{|c|c|c|c|c|c|c|c|c|c|c|c|c|}
\hline \multirow{2}{*}{ 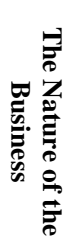 } & \multirow[b]{2}{*}{ 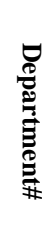 } & \multirow[b]{2}{*}{$\begin{array}{l}\overrightarrow{2} \\
w^{2} \\
\#\end{array}$} & \multirow[b]{2}{*}{$\mathbb{N}$} & \multicolumn{9}{|c|}{ Available Features } \\
\hline & & & & $\begin{array}{l}3 \\
\vdots \\
0 \\
0 \\
0 \\
0\end{array}$ & 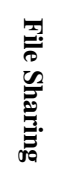 & & 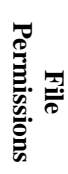 & 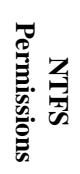 & 胥. & 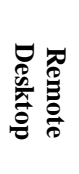 & 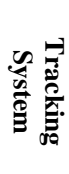 & 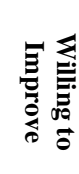 \\
\hline \multirow{6}{*}{ 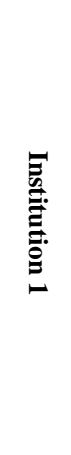 } & 1 & 3 & Yes & Yes & Yes & Yes & Yes & Yes & Yes & No & Yes & No \\
\hline & 2 & 5 & Yes & Yes & Yes & Yes & Yes & Yes & Yes & No & No & No \\
\hline & 3 & 10 & Yes & Yes & Yes & Yes & Yes & Yes & Yes & No & Yes & Yes \\
\hline & 4 & 3 & Yes & Yes & Yes & Yes & Yes & Yes & Yes & No & Yes & Yes \\
\hline & 5 & 3 & Yes & Yes & Yes & Yes & Yes & Yes & Yes & No & Yes & No \\
\hline & 6 & 2 & Yes & Yes & Yes & Yes & Yes & Yes & Yes & No & Yes & No \\
\hline \multirow{6}{*}{ 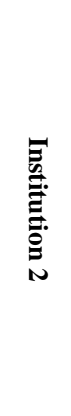 } & 1 & 5 & No & Yes & No & No & No & No & No & No & No & Yes \\
\hline & 2 & 3 & No & Yes & No & No & No & No & No & No & No & Yes \\
\hline & 3 & 3 & No & Yes & No & No & No & No & No & No & No & Yes \\
\hline & 4 & 2 & No & Yes & No & No & No & No & No & No & No & Yes \\
\hline & 5 & 4 & No & Yes & No & No & No & No & No & No & No & Yes \\
\hline & 6 & 4 & No & Yes & No & No & No & No & No & No & No & Yes \\
\hline 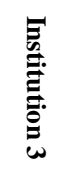 & 1 & 4 & Yes & Yes & Yes & No & Yes & Yes & Yes & No & No & Yes \\
\hline 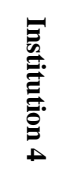 & 1 & 3 & No & Yes & No & No & No & No & No & No & No & Yes \\
\hline 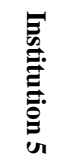 & 1 & 12 & Yes & Yes & Yes & Yes & Yes & Yes & Yes & Yes & No & Yes \\
\hline \multirow{3}{*}{ 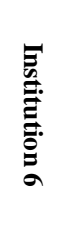 } & 1 & 3 & Yes & Yes & Yes & Yes & Yes & Yes & No & No & No & Yes \\
\hline & 2 & 6 & Yes & Yes & Yes & Yes & Yes & Yes & No & No & No & Yes \\
\hline & 3 & 5 & Yes & Yes & Yes & Yes & Yes & Yes & No & No & No & Yes \\
\hline \multirow{2}{*}{ 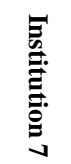 } & 1 & 3 & No & Yes & No & No & No & No & No & No & No & Yes \\
\hline & 1 & 4 & No & Yes & No & No & No & No & No & No & No & Yes \\
\hline
\end{tabular}




\section{THE PROPOSED P2P-STS DESIGN AND IMPLEMENTATION}

The P2P-STS comes up with an optimized practice solution in using and utilizing the vital main features of P2P network, especially the "tracking system". The P2P-STSis able to track and trace vital information about the documents in an efficient and trustworthy manner. This is depicted in Figure 13.

Firstly, the documents need to be registered by the P2P-STS either by a) placing RFID Tag on the document and then scanning the RFID Tag using the handheld device orb) adding them manually by the P2P-STS.

Secondly, track documents using an antenna. Antenna will detect a document movement. Therefore, if somebody takesa document from a specific place and go to any other location in the premise, the antenna will track and identify the exact location of the document. This is depicted in Figure 14.
Finally, search for a specific document by the handheld device. The Hardware and Software of P2P-STS are depicted in the Figure 15 and Figure 16.

In addition to the location and movement of all your documents that are on the system can be tracked throughout your premise. The P2P-ST can provide the following features:

- Control documents usage and increase accountability through report generation tools.

- Documents subject to access control options. Therefore, only authorized users are eligible to access them.

- Not only your documents better managed but scanned documents can be linked for a better accessibility.

- Track the lifecycle of your documents from creation to storage through regular retrievals and use. Also to secure destruction according to your retention schedule.

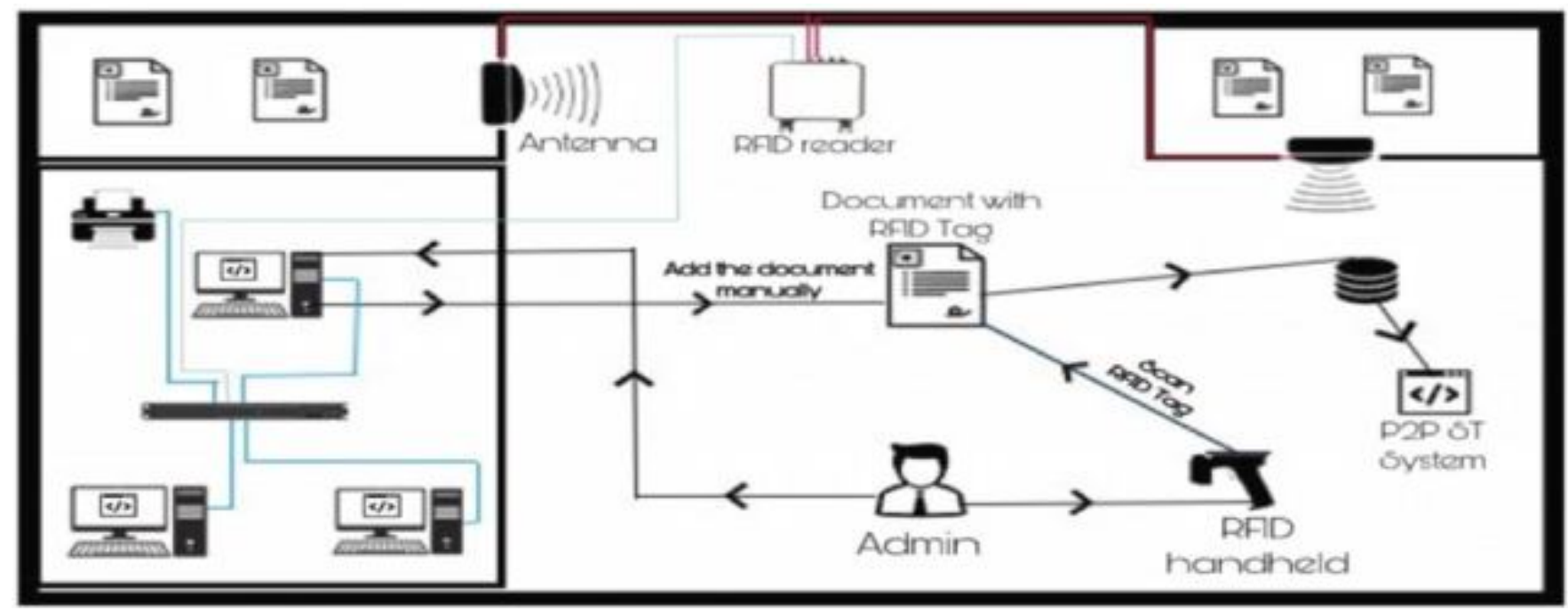

Figure 13: P2P-STS Diagram

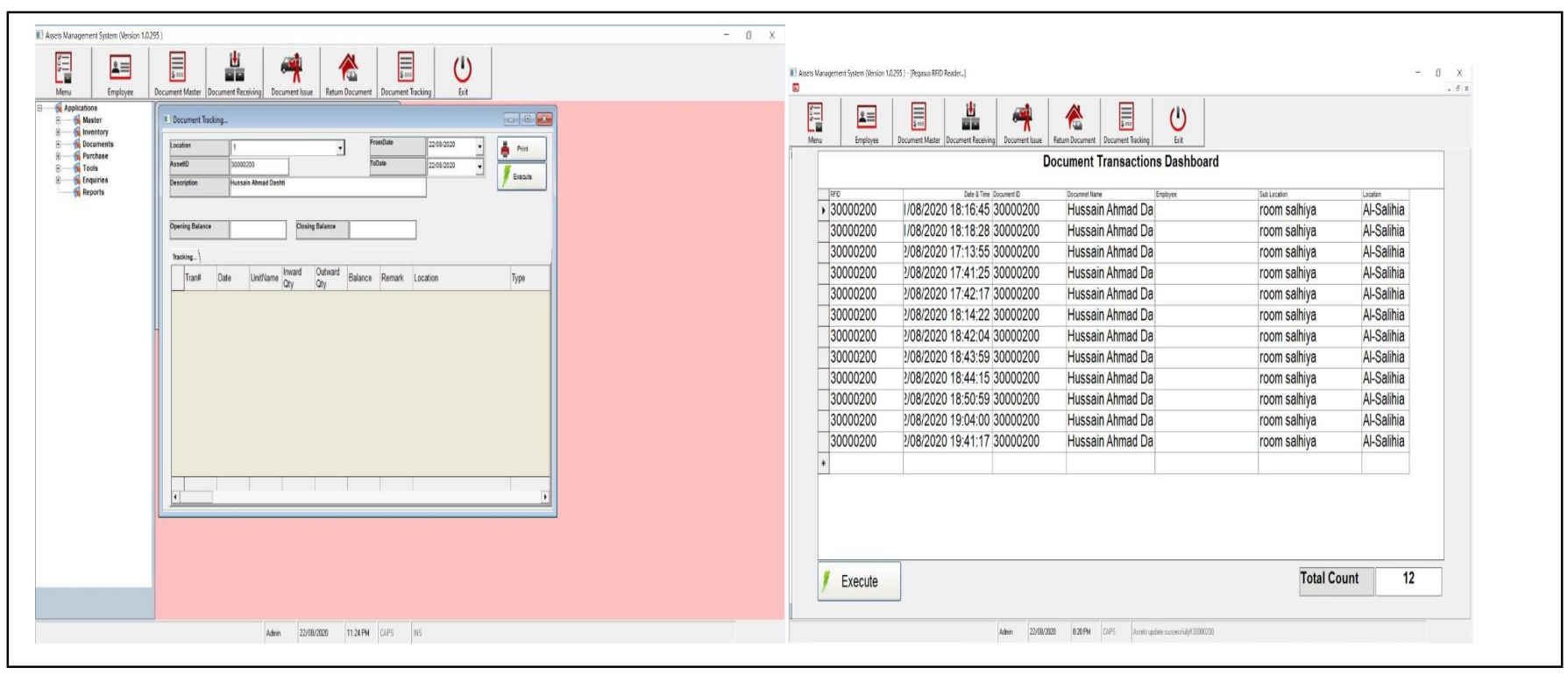

Figure 14: P2P-STS Scenario 


\begin{tabular}{|c|c|c|}
\hline \multicolumn{3}{|c|}{ Hardware } \\
\hline Computer & Switch & LAN Cable \\
\hline $\begin{array}{l}\text { - Discription: The computer is } \\
\text { used for creating the whole } \\
\text { database and building P2P- } \\
\text { STS } \\
\text { - Specifications: } \\
\text { - win } 10 \\
\text { - core i7 processor } \\
\text { - } 16 \text { GB RAM } \\
\text { - NVIDIA GTX GPU }\end{array}$ & $\begin{array}{l}\text { - Discription:The switch is used to } \\
\text { make a netwrok between the } \\
\text { computers } \\
\text { - Specifications: } \\
\text { - dimensions } 134.5 \times 79 \times 22.5 \mathrm{~mm} \\
\text { - } 8 \text { ports } \\
\text { - } 1.6 \mathrm{Gbps} \text { switching capacity }\end{array}$ & $\begin{array}{l}\text { - Discription:The LAN cable is } \\
\text { used to make a connection } \\
\text { between pcs, switches and other } \\
\text { devices } \\
\text { - Specifications:- } \\
\text { - Cat6 } \\
\text { - Straight cable } \\
\text { - } 10 \text { meters }\end{array}$ \\
\hline Coaxial Cable & Router & RFID READER \\
\hline $\begin{array}{l}\text { - Discription: Coaxial cable is used } \\
\text { as a transmission line for radio } \\
\text { frequency signals. It will be used } \\
\text { to connect the antenna with the } \\
\text { RFID reader } \\
\text { - Specifications: } \\
\text { - weidht } 26 \mathrm{lbs} \\
\text { - min temperature }-40 \mathrm{C} \\
\text { - max temperature } 80 \mathrm{C} \\
\text { - max frequency } 5 \mathrm{GHz} \\
\text { - max voltage } 1900 \mathrm{~V}\end{array}$ & $\begin{array}{l}\text { - Discription: Router is used to } \\
\text { connect to the Internet } \\
\text { - Specifications: } \\
\text { - Size: } 103^{*} 103 * 225 \mathrm{~mm} \\
\text { Weight: }<1000 \mathrm{~g} \\
\text { - } 2.4 \mathrm{GHz} \& 5 \mathrm{GHz} \mathrm{WiFi} \\
\text { - power AC: } 100 \mathrm{~V} \sim 240 \mathrm{~V} ; \\
\text { DC: } 12 \mathrm{~V}, 2 \mathrm{~A}\end{array}$ & $\begin{array}{l}\text { - Discription: RFID reader is used } \\
\text { to gather information from RFID } \\
\text { tag to track individual objects } \\
\text { - Specifications: } \\
\text { - dimension } 19.56 \mathrm{~cm} \times 14.99 \mathrm{~cm} \\
\text { x } 4.32 \mathrm{~cm} \\
\text { - weight } 1.91 \mathrm{bs} \pm 0.1 \mathrm{lbs} \\
\text { - operating temperature }-20^{\circ} \text { to } \\
\text { +55 C } \\
\text { - processor Texas Instruments } \\
\text { AM3505 (600 Mhz) } \\
\text { - memory Flash } 512 \mathrm{MB} \text {; DRAM } \\
256 \mathrm{MB} \\
\text { - operating system Linux }\end{array}$ \\
\hline
\end{tabular}

Figure 15:Hardware of P2P-STS

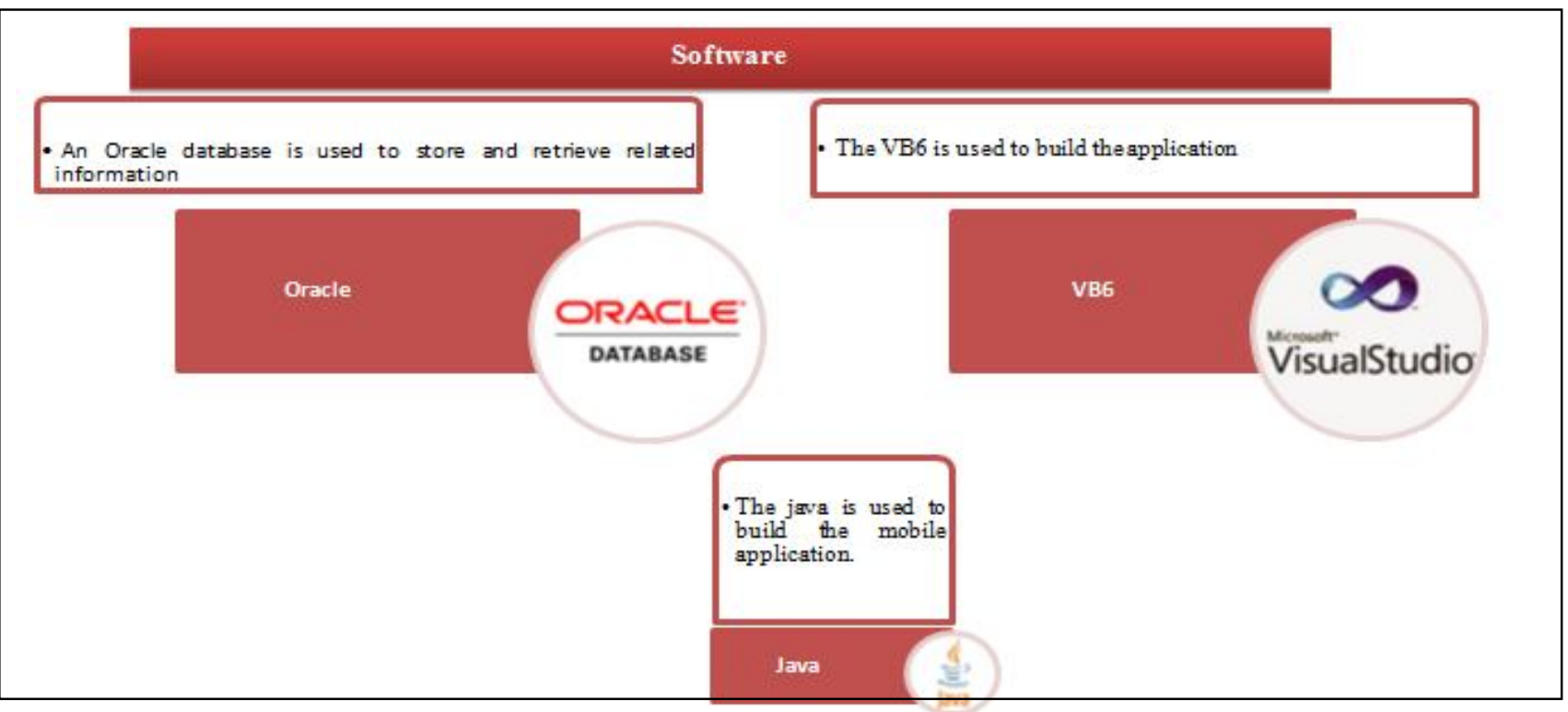

Figure 16:Software of P2P-STS 


\section{CONCLUSION}

This paper has thoroughly analyzed several real small businesses in Kuwait whether they use a P2P network or not (P2P vs. non-P2P). We have concentrated on eight features of P2P: Windows version, file sharing, map drive, file permissions, NTFS permissions, sharing printer, remote desktop and tracking system. It has been concluded that the most of P2P businesses have not effectively use these features, especially the "tracking system". Therefore, P2P-STS has come up with an optimized practice solution in using and utilizing the vital main features of P2P network, especially the "tracking system".

\section{REFERENCES}

1. O. Khattab, H. Alzayed, A. Almutairi and Z. Yousef, Conducting Empirical Research Study: How to Effectively and Securely Use the Vital Features of the Active Directory Network Server, International Journal of Advanced Trends in Computer Science and Engineering, vol. 9, no. 1, pp. 87-90, Jan- Feb 2020.
2. S. Vimal and S.K Srivatsa,A Survey on Various File Sharing Methods in P2P Networks, $3^{\text {rd }}$ International Conference on Science Technology Engineering \& Management, Chennai, 2017, pp. 305-310.

3. Peer-to-Peer (P2P): Advantages and Disadvantages. Retrieved15Jun2020from:https://www.ianswer4u.com/2 011/05/peer-to-peer-network-p2p-advantages-and.html.

4. S. Iwata, T. Ozono and T. Shintani, Any-Application Window Sharing Mechanism Based on Web RTC, $6^{\text {th }}$ IIAI International Congress on Advanced Applied Informatics (IIAI-AAI), Hamamatsu, 2017, pp. 808-813.

5. P. Podduturi, P. Ahmadi, K. Islam and T. Maco, RFID Implementation in Supply Chain Management Using P2P Network Overlays, Wireless Telecommunications Symposium, USA, 2019, pp. 1-7.

6. E. Cirillo, P. Minosi, F. Marzoli, I. Sergi, R. Colella, L. Patrono, L. Catarinucci and S. Pieretti, Opportunity to Analyze Laboratory Mice Behavior by Tracking Systems based on UHF RFID Technology: Pros and Cons, IEEE International Conference on RFID Technology and Applications, Italy, 2019, pp. 427-432. 